RUNNING HEAD: Norms for Executive Functions tests in Portugal

\title{
Normative data for tests of Attention and Executive Functions in a sample of European Portuguese adult population
}

Selene G. Vicente ${ }^{a}$, Diego Rivera ${ }^{\mathrm{b}}$, Fernando Barbosa ${ }^{\mathrm{c}}$, Nuno Gaspar ${ }^{\mathrm{a}}$, Artemisa R. Dores ${ }^{\mathrm{c}, \mathrm{d}}$, Guido Mascialino ${ }^{\mathrm{e}}$, and Juan Carlos Arango Lasprilla ${ }^{\mathrm{f}, \mathrm{g}, \mathrm{h} *}$

${ }^{a}$ Centre for Psychology, Faculty of Psychology and Education Sciences, University of Porto, Porto, Portugal; ${ }^{b}$ Departamento de Ciencias de la Salud, Universidad Pública de Navarra, Navarra, España; 'Laboratory of Neuropsychophysiology, Faculty of Psychology and Education Sciences, University of Porto, Portugal; ${ }^{d}$ School of Health, Polytechnic of Porto, Porto, Portugal; ${ }^{e}$ School of Psychology, Universidad de Las Américas, Quito, Ecuador; fIKERBASQUE. Basque Foundation for Science, Bilbao, Spain; ${ }^{g}$ Biocruces Bizkaia Health Research Institute, Barakaldo, Spain; ${ }^{h}$ Department of Cell Biology and Histology, University of the Basque Country (UPV/EHU), Leioa, Spain

*Corresponding author:

Grupo de Psicología y Salud

Biocruces Bizkaia Health Research Institute.

IKERBASQUE. Basque Foundation for Science.

Plaza de Cruces s/n. 48903

Barakaldo, Bizkaia, Spain.

Phone: (34) 946006000 (Ext. 7963)

E-mail: jcalasprilla@gmail.com

This is an accepted manuscript of an article published by Taylor \& Francis in Aging, Neuropsychology and Cognition on 12 Jul 2020, available online: https://doi.org/10.1080/13825585.2020.1781768 
RUNNING HEAD: Norms for Executive Functions tests in Portugal

\section{Normative data for test of Attention and Executive Function in a sample of European Portuguese adult population}

Objective: The main goal of this study was to produce normative data for the Portuguese population on five neuropsychological tests frequently used to assess executive functions and attention: the Modified Wisconsin Card Sorting Test (M-WCST), the Stroop Color and Word Test, the Trail Making Test (TMT), the Brief Test of Attention (BTA), and the Symbol Digit Modality Test (SDMT). Method: The study included 300 individuals aged between 18 and 93 years, who had educational backgrounds ranging from 3 to 25 years. Results: The influence of age, education, and sex were explored for each measure, as well as their contribution to explain the performance variance. Conclusions: The normative data are presented as regression-based algorithms to adjust direct and derived test scores for sex, age, and education. This study provides a calculator of normative data, derived from the results of the regression models.

Keywords: Executive functions; attention; neuropsychological tests; standardization; European Portuguese; normative data 
RUNNING HEAD: Norms for Executive Functions tests in Portugal

\section{Introduction}

Executive functions and attentional processes have been defined as multifaceted constructs and are acknowledged to represent a highly complex set of cognitive abilities, which are critical for everyday adaptive function. Executive Functions (EFs) are an umbrella term for a collection of interrelated processes which are responsible for goal-directed behavior and have been referred as the "supervisor" which controls, organizes, and directs cognitive activity, emotional responses and behaviour, allowing individuals to respond adaptively to their environment.

When these executive control systems break down, behaviour becomes poorly controlled and disinhibited; therefore coordination, control and goal-orientation are at the heart of the concept of EFs. Core EFs are inhibition, working memory, cognitive flexibility, decision-making, self-monitoring and planning (Goldstein, Naglieri, Princiotta, \& Otero, 2014; Jurado \& Rosselli, 2007; Lezak, Howieson, Bigler, \& Tranel 2012; Packwood, Hodgetts, Tremblay, 2011; Strauss et al., 2006; Stuss, 2011), carried out by prefrontal areas of the frontal lobes and which include frontal and posterior regions of the cerebral cortex, as well as subcortical regions (Burzynska et al., 2012; Robinson, Calamia, Glascher, Bruss, \& Tranel, 2014).

Attention is in turn a foundational ability necessary for effective performance in all other cognitive domains. It can be broadly defined as an information filter and facilitator of focused behavior (Lezak et al., 2012; Strauss et al., 2006). As is the case for EFs, attention processes are multidimensional comprising several subdomains including stimuli selection, sustained focus, and mental flexibility or alternating attention (Baddeley, 1998; Petersen \& Posner, 2012; Sohlberg \& Mateer, 2002).

According to some authors, the neurocognitive domain of complex attention is composed of four key subdomains: sustained, divided and selective attention and 
RUNNING HEAD: Norms for Executive Functions tests in Portugal

processing speed (Sachdev et al., 2014). Some models of attention conceptualize it as inherently related to executive processes, and as such are often considered overlapping domains in neuropsychological evaluation (Baddeley, 1998; Lezak et al., 2012).

Executive and attentional dysfunction are common in a wide variety of conditions including acquired brain injury (e.g., TBI: Caeyenberghs et al., 2014; Cicerone \& Giacino, 1992; McDonald, Flashman, \& Saykin, 2002; Shah et al., 2017; Tramontana, Cowan, Zald, Prokop, \& Guillamondegui, 2014), stroke (Olgiati, Russell, Soto, \& Malhotra, 2016; Pohjasvaara et al., 2002; Vataja et al., 2003), neuropsychiatric (e.g., bipolar depression: Caixeta et al., 2017; and schizophrenia: Carter et al., 2010; Dirnberger, Fuller, Frith, \& Jahanshahi, 2014; Gavilán \& García-Albea, 2015), neurodegenerative (e.g., Alzheimer's disease: Amiéva et al., 2004; Binetti et al., 1996; Firbank et al., 2016; Moreira, Lima, Vicente, 2014; Moreira, Costa, Machado, Castro, Lima, \& Vicente, 2019; Swanberg, Tractenberg, Mohs, Thal, \& Cummings, 2004; the behavioral-variant frontotemporal dementia, bvFTD: Fiorentino et al., 2013; Slachevsky et al., 2004; and Parkinson's: Dirnberger \& Jahanshahi, 2013; Lima, Meireles, Fonseca, Castro, \& Garret, 2008; Papagno \& Trojano, 2018; Zgaljardic et al., 2006), and neurodevelopmental disorders (e.g., ADHD: Kingdon, Cardoso, \& McGrath, 2016; Margari et al., 2016; Veloso, Vicente, \& Filipe, 2020; and autism: Filipe, Frota, \& Vicente, 2019; Miller \& Hinshaw, 2015), among many others conditions.

Given the multidimensional nature of these two constructs, there are several instruments to assess executive functions and attention neurocognitive subdomains (Lezak et al., 2012; Mitrushina, 2005). Among the large amount of comprehensive neuropsychological assessment tests of EFs and attention, we highlight here a set of the most frequently used in clinical and research context and for which we intend to collect normative data for European Portuguese: (1) the Modified Wisconsin Card Sorting Test 
RUNNING HEAD: Norms for Executive Functions tests in Portugal

(M-WCST; Nelson, 1976; Schretlen, 2010); (2) the Stroop Color and Word Test

(Golden \& Freshwater, 2002; Stroop, 1935); (3) the Brief Test of Attention (Schretlen, 1997); (4) the Trail Making Test (TMT; Army Individual Test Battery, 1944); and (4) the Symbol Digit Modality Test (SDMT; Smith, 1991).

Although several studies have been conducted to derive normative data for English and Spanish speaking populations (Arango-Lasprilla et al., 2015a; ArangoLasprilla et al., 2015b; Arango-Lasprilla et al., 2015c; Rivera et al., 2015a; Rivera et al., 2015b) there is a dearth of data regarding European Portuguese speakers. The main goal is to obtain regression-based normative data for a Portuguese population, ages 18 to 95 years, adjusted by age, sex, and education, variables associated with performance in prior studies.

\section{Method}

\section{Participants}

300 healthy individuals from Porto District, Portugal, composed the study sample. Sixty-two percent of the sample were woman, and the average age and education were $50.4 \pm 21.2$ and $10.4 \pm 5.2$ years, respectively. The maximum error was established using classical estimation assuming infinite (very large) population sizes, where the case of maximum uncertainty was assumed $(\pi=1-\pi=.5)$ and a confidence interval of $95 \%$. The maximum error of the sample size was $\approx .056$ (accuracy level $\approx$ 94.4\%). The Sample's demographic information can be found in the Table 1. 
RUNNING HEAD: Norms for Executive Functions tests in Portugal

To participate in the study, it was necessary to meet the following inclusion/exclusion criteria: a) age between 18-95 years; b) were born and currently live in Portugal; c) have Portuguese as the mother tongue; d) had completed at least one year of formal education; e) be literate; f) not to have cognitive impairment, determined through a score $\geq 23$ on the Mini-Mental State Examination (MMSE; Folstein, Folstein, \& McHugh, 1975); g) not to have symptoms of depression, determined through a score $\leq 4$ on the Patient Health Questionnaire-9 (PHQ-9; Kroenke, Spitzer, \& Williams, 2001); h) be completely independent for activities of daily living, determined through a score $\geq 90$ on the Barthel Index (Mahoney \& Barthel, 1965); i) not to have neurological or psychiatric conditions; j) not to have history of drug abuse; k) not to have pain or other medication regularly that may impact cognitive functioning; and 1) not to have severe visual and/or hearing deficits. Participation in the study was completely voluntary and without any economic reward.

\section{Instruments and measures administration}

Self-report questionnaire. A researcher-created questionnaire was used to collect information about the participants' medical history, sociodemographic, and health status.

\section{Modified Wisconsin Card Sorting Test (M-WCST; Schretlen, 2010). The M-} WCST is a widely used test designed to measure several subdomains of EFs such as problem solving, concept formation, and mental flexibility (Lezak et al., 2012; Strauss et al., 2006; Zubicaray \& Ashton, 1996). The M-WCST consists of four stimulus cards and 48 response cards. Each card varies in shape (cross, circle, triangle or star), color (red, blue, yellow or green), and number (one to four). The participant is asked to match the response cards to the stimulus cards in accordance to a categorical rule that is not 
RUNNING HEAD: Norms for Executive Functions tests in Portugal

disclosed, which the participant must infer from the examiner's feedback about the correctness of their choice. The participant must correctly classify six consecutive cards to complete a category. The test continues until all six categories are classified or until the whole response deck has been used (Schretlen, 2010). The test allows for calculation of number of categories, perseverations, and total errors. M-WCST possesses good psychometric properties including adequate test-retest reliability (Lineweaver, Bondi, Thomas, \& Salmon, 1999), a theoretically sound factor structure (Nagahama et al., 2003). In this study a translated European Portuguese instruction by special permission of the Publisher, Psychological Assessment Resources Inc. (PAR) were used.

Portuguese version of The Stroop Color and Word Test (Fernandes, 2012). The Stroop test provides measures of inhibition, selective attention, and mental flexibility (Lezak et al., 2012; Strauss et al., 2006). The Stroop Color and Word Test consists of three pages with one hundred components randomly organized into five columns. On the first page the participant must read aloud the words "Red", "Green", and "Blue" printed in black ink. On the second page, the participant must name the color (blue, green or red) of the ink in which the element "XXXX" is printed. And on the third one, the participant must name the color of the ink, inhibiting the reading of the word that corresponds to the name of another color. The subject has 45 seconds to read aloud, as quickly as possible. Psychometric properties of the Stroop Color and Word Test have been widely studied and reported as good (for reviews see Strauss et al., 2006).

Trail Making Test (TMT; Reitan, 1958). The Trail Making Test (TMT) is considered a test of attention, mental flexibility, and processing speed (Lezak et al., 2012; Spreen \& Strauss, 1998). The TMT consists of two parts (A \& B) in which the task is to connect randomly distributed elements. In part A, all stimuli are numbers, 
RUNNING HEAD: Norms for Executive Functions tests in Portugal

which the participant must connect with a line (1-2-3 . . 15). In part B, the participant must alternate between numbers and letters (1-A, 2-B, 3-C. . ). The total score is the number of seconds that the participant needs to complete the task, with a time limit of 60 and 150 seconds for TMT-A and TMT-B respectively. TMT-A and TMT-B have high test-retest reliability, at least .76 for Part A, and .82 for Part B (Lezak et al., 2004; Seo et al., 2006; Wagner, Helmreich, Dahmen, Lieb, \& Tadic, 2011).

Symbol Digit Modalities Test (SDMT; Smith, 1982). SDMT is a test to measure divided attention, visual scanning, and processing speed (Arango-Lasprilla et al., 2015). The protocol contains a key with two rows, with nine stimulus symbols in the upper row and matched numbers (1-9) in the row below it. Participants are then presented with rows than contain the symbols but not the numbers, and asked to write in as many numbers as possible in 90 seconds. Oral and written versions exist. This study developed normative data for the written form. The total score corresponds to the number of correct substitutions achieved (Smith, 1982). SDMT has good test-retest reliability in healthy adults' samples (.74 to .93; Arango-Lasprilla et al., 2015).

The Brief Test of Attention (BTA; Schretlen, Bobholz, \& Brandt, 1996). The BTA is a measure of divided attention and is composed of two parts, each with 10 alphanumeric items. In the BTA-N, the participant must count the number of numbers contained in each stimulus that the evaluator read aloud. In the BTA-L, however, it is the letters that have to count. Psychometric properties include high reliability $(\alpha=.80)$ and good test-retest stability (.70, Schretlen, 1997). While age and sex effects have been noted (Schretlen, 1997), their effect appears to be small (Strauss et al., 2006). The score is the number of correct answers, being 20 points the maximum score. We used the instructions that were translated to European Portuguese by special permission of the Publisher, Psychological Assessment Resources Inc. (PAR). 
RUNNING HEAD: Norms for Executive Functions tests in Portugal

\section{Procedure}

Portuguese participants were recruited from several contexts: educational (universities), elderly care institutions, social (e.g., sportive, cultural), health care services and others. Recruitment information was also posted in several institutions and disseminated online. The Communication Service of the Faculty of Psychology and Educational Sciences of the University of Porto, Portugal, also participated in the dissemination of the recruitment information. Two Portuguese psychologists were recruited and trained to conduct the neuropsychological assessments. The administration of the neuropsychological protocol took approximately 50 minutes for younger participants (age $<50$ years old) and 90 minutes for older ones and was conducted in a single day. Data collection took place over a period of six months in the district of Porto, Portugal. Each participant was tested individually in a quiet room made available in the several assessment contexts: universities, elderly care institutions, hospitals, and homes. The order of administration of the tests was randomized. A random list was made available by the coordinator of the multicenter study where the order of administration of the tests for each participant was pre-defined. All the participants completed and signed an informed consent before the administration in accordance with the Helsinki Declaration. The study was approved by the Ethics Committee of the Ethics committee of University of Porto.

\section{Statistical Analyses}

\section{Exploratory data analysis}

Pearson correlations between the M-WCST (Categories, Perseverative errors, and Total errors), Stroop test (Word, Color, Word-Color, and Interference), TMT (A and B), SDMT, and BTA scores and the sociodemographic (age, education, and sex) 
RUNNING HEAD: Norms for Executive Functions tests in Portugal

variables were computed.

Insert Table 2

Demographic effects and generation of normative data

M-WCST (Categories, Perseverative errors, and Total errors), Stroop test

(Word, Color, Word - Color, and Interference), TMT (A and B), SDMT, and BTA scores were computed separately. The effects of demographic variables on each score were evaluated by means of multiple linear regression analyses. Age, age ${ }^{2}$, education, education $^{2}$, sex, and all two-way interactions between these variables were included as predictors in the full regression models. Age and education were centered (calendar age in years - mean age in the sample; education in years - mean education in the sample) before computing the quadratic age and education to avoid multicollinearity (Aiken, West, \& Reno, 1991). Squared terms of age and years of education were added in the full model to allow for quadratic effects between these independent variables and tests scores. Sex was dummy coded as $\operatorname{man}=1$ and woman $=0$. The full regression model can be formally described as: $y_{i}=B_{0}+B_{1} \cdot\left(A g e-\dot{x}_{A g e}\right)_{i}+B_{2} \cdot\left(A g e-\dot{x}_{A g e}\right)_{i}^{2}+$ $B_{3} \cdot\left(\text { Education }-\dot{x}_{E d u .}\right)_{i}+B_{4} \cdot\left(\text { Education }-\dot{x}_{E d u}\right)_{i}^{2}+B_{5} \cdot \operatorname{Sex}_{i}+B_{k} \cdot$ Interactions $_{i}+\varepsilon_{i}$, with the subscript $i$ referring to the participants $(i=\{1,2, \ldots$, $300\})$, the subscript $\mathrm{k}$ referring to the regression parameters $(k=\{1,2, \ldots, \mathrm{K}\}, \mathrm{K}=$ the number of fixed-effects in the model including the intercept), and the term Interactions $s_{i}$ being a short-hand notation to refer to all two-way interactions between the fixed effects. The model assumes that the residuals $\varepsilon_{i}$ are normally distributed with 
RUNNING HEAD: Norms for Executive Functions tests in Portugal

mean 0 and variance $\sigma_{\varepsilon}^{2}$, i.e., $\varepsilon_{i} \sim N\left(0, \sigma_{\varepsilon}^{2}\right)$.

Independent variables that were not statistically significant in the multiple regression model were removed, and a reduced model was fitted again. A Bonferronicorrected $\alpha$-level of $.005(=.05 / 12[$ number of predictors] $=.004 \cong .005)$ was used. Predictors that were also included in a higher order term in the multiple regression model (quadratic variables and interactions) were not removed (Aiken, West, \& Reno, 1991). For all multiple linear regression models, the following assumptions were evaluated: a) multicollinearity (Variance Inflation Factor [VIF] which must be $\leq 10$ ), b) homoscedasticity (participants were grouped into quartiles of the predicted scores and the Levene's test was applied on the residuals), c) normality of the standardized residuals (Kolmogorov-Smirnov test), and d) existence of influential values assess using maximum Cook's distance, and subsequently related to an $F(p, n-p)$ distribution, where $p$ is the number of regression parameters (including the intercept) and $n$ is the sample size. Influential values are considered when the obtained percentile value is equal or higher than 50 (Kutner et al., 2005). An $\alpha$-level of .005 was used in all analyses.

Finally, a four-step procedure was performed for each score, separately, to generate normative data adjusted by sociodemographic variables (Rivera et al., 2019; Van Breukelen \& Vlaeyen, 2005; Van der Elst, van Boxtel, Van Breukelen, \& Jolles, 2006a; Van der Elst, van Boxtel, Van Breukelen, \& Jolles, 2006b): (a) the expected test score $\left(\hat{Y}_{i}\right)$ is computed based on the fixed effect parameter estimates of the established final regression model: $\hat{Y}_{i}=B_{0}+B_{1} X_{1 i}+B_{2} X_{2 i}+\cdots+B_{K} X_{K i}$; (b) To obtain the residual value $\left(e_{i}\right)$, a subtraction between the raw score of the neuropsychological test $\left(Y_{i}\right)$ and the predicted value previously calculated was performed $\left(\hat{Y}_{i}\right)$, as shown in the following formula: $e_{i}=Y_{i}-\hat{Y}_{i}$. For M-WCST Perseverative errors, M-WCST Total errors, and 
RUNNING HEAD: Norms for Executive Functions tests in Portugal

TMT (A and B) scores, minus sing must be added in the formula $\left(e_{i}=-\left[Y_{i}-\hat{Y}_{i}\right]\right)$ due to its interpretation (i.e. lower scores corresponds to better performance). (c) Using the residual standard deviation $\left(S D_{e}\right)$ value provided by the regression model, residuals were standardized: $z_{i}=e_{i} / S D_{e} ;$ (d) Finally, using the standard normal cumulative distribution function, the exact percentile corresponding to the $z$-score previously calculated was obtained (if the model assumption of normality of the standardized residuals was met in the normative sample), or via the empirical cumulative distribution function of the standardized residuals (if the standardized residuals were not normally distributed).

Adjusted $R^{2}$ values are provided for all final models. All analyzes were performed using SPSS Version 23 (IBM Corp., Armonk, NY) and R 3.4 .2 for Windows (R Development Core Team, 2017).

\section{Results}

\section{Exploratory data analysis}

The intercorrelations between age and M-WCST Categories, Stroop test (Word, Color, Word-Color, and Interference), SDMT, and BTA scores were significantly negative (all $\mathrm{r} \leq .542$, all $\mathrm{p}<.001$ ), while the intercorrelations between these scores and education were significantly positive (all $\mathrm{r} \geq .489$, all $\mathrm{p}<.001$ ). Otherwise M-WCST Perseverative errors, Total errors, TMT (A and B), and age correlated significantly positive (all $\mathrm{r} \geq .651$, all $\mathrm{p}<.001$ ), while education and these scores correlated significantly negative (all $\mathrm{r} \leq .652, \mathrm{p}<.001)$ (see Table 2$)$.

\section{Final regression model - Assumptions}

The assumptions of multiple linear regression analyses were largely met for all final models. There was no multicollinearity (the VIF values in all models were at most 
RUNNING HEAD: Norms for Executive Functions tests in Portugal

2.669 , and thus well below the threshold value of 10 that is indicative for multicollinearity; collinearity tolerance values did not exceed the value of 1 or influential cases (the maximum Cook's distance value was .190; relating this value to an $\mathrm{F}(5,295)$ distribution yields percentile value 3 , which is well-below the threshold percentile value of 50 that is indicative for the presence of influential cases). The Levene's test suggested that there was heteroscedasticity in all models except in the Stroop test (Word, Color, and Interference) and SDMT scores. Standardized residuals of the models were normally distributed (as evaluated with the Kolmogorov-Smirnov test) except for M-WCST Categories and Perseverative errors.

\section{$M-W C S T$}

The final multiple linear regression models for M-WCST Categories, Perseverative errors, and Total errors scores were significant (see Table 3). M-WCST Categories score was negatively influenced by quadratic age and increased curvilinearly as a function of education, so that young people have better scores than older people, improving performance as the years of education increase, until 15 years, when the execution stabilizes (see Figure 1A). The amount of variance (adjusted for the number of predictors in the final model; adjusted $\mathrm{R}^{2}$ ) explained by these predictors was $59 \%$. MWCST Perseverative errors score was positively influenced by quadratic age and decreased curvilinearly as a function of education, so that a decrease in errors is observed up to 15 years of education, at which time there is a slight increase. The amount of variance explained by these predictors was 59\%. Finally, M-WCST Total errors scores were positively influenced by quadratic age and decreased curvilinearly as a function of education, so that the scores remain stable during the first 40 years of age, and thereafter a curvilinear increase is observed up to 90 years. In addition, people with less than 10 years of education have a much worse performance compared to people 
RUNNING HEAD: Norms for Executive Functions tests in Portugal

with more years of education (see Figure 1B). The amount of variance explained by these predictors was $62 \%$.

Insert Figure 1; Table 3

Stroop Word-color test

The final multiple linear regression models for Stroop Word, Color, Word-color, and Interference scores were significant (see Table 4). Stroop Word decreased curvilinearly as a function of age and increased curvilinearly as a function of education, showing a subtle decrease of the scores until 45 years of age and a steeper decrease from 45 to 90 years, with people with more years of education performing better than people with fewer years of education. Stroop Color was negatively influenced by quadratic age and increased linearly as a function of education, so that the performance remains practically stable until the age of 35 , moment from which a progressive decrease is shown as the age advances. For Stroop Word-color score an interaction between age and sex was found, so that men outperform women until 55 years, but after 65 years, women perform better than men (see Figure 1C). Finally, Stroop interference was negatively influenced by age, which means that the older the age the higher the interference. The amount of variance explained by these predictors for Stroop Word, Color, Word-color, and Interference scores were $60 \%, 59 \%, 68 \%$, and $37 \%$, respectively.

Insert \& Table 4 
RUNNING HEAD: Norms for Executive Functions tests in Portugal

TMT

The final multiple linear regression models for TMT-A and TMT-B scores were significant (see Table 5). TMT-A and TMT-B scores were positively influenced by quadratic age and decreased curvilinearly as a function of education, so that the time needed to complete the test decreases as the years of education increases, until 15 year when the performance stabilizes. In addition, young people have a better performance than older people (see Figure 1D). The amount of variance explained by these predictors for TMT-A and TMT-B scores were $71 \%$ and $78 \%$, respectively.

Insert Table 5

$S D M T$

The final multiple linear regression model for SDMT score was significant (see Table 6). The SDMT score was negatively influenced by quadratic age and increased curvilinearly as a function of education, so the performance decreases as the age advances, with people with more years of education having better performance than those with less years of education (see Figure 1E). The amount of variance explained by these predictors was $79 \%$.

Table 6

$B T A$

The final multiple linear regression models for BTA score was significant (see 
RUNNING HEAD: Norms for Executive Functions tests in Portugal

Table 6). The BTA score was affected by a quadratic age effect and increased curvilinearly as a function of education, showing a subtle decrease of the scores until 50 years of age and a steeper decrease from this age to 90 years, with people with more years of education performing better than people with fewer years of education (see Figure $1 \mathrm{~F})$. The amount of variance explained by these predictors was $41 \%$.

\section{Calculator of Normative Data}

The four-step normative procedures explained above offer the clinician the ability to determine an exact z-scores and percentile for a participant who has a specific score on the M-WCST, Stroop test, TMT, SDMT, and BTA tests. However, this method can be prone to human error due to the number of required computations by hand. To enhance user-friendliness, the authors created a calculator in Microsoft Excel using these steps in which the clinician must include the following information: raw score (MWCST (Categories, Perseverative errors, and Total errors), Stroop test (Word, Color, Word-color, and Interference), TMT (A and B), SDMT, and BTA), age, education, and sex to calculate the z-score and percentile automatically. This tool is freely available for all users and may be downloaded at www.masked.com.

\section{Discussion}

The aim of this study was to generate normative data for five neuropsychological tests of EFs and attention for the adult population in Portugal, while considering the impact of age, sex, and level of education on performance. Additionally, this study offers a calculator of normative data, derived from the results of the regression models, which streamlines the process of obtaining normed scores thereby diminishing human errors that may happen when using tables. 
RUNNING HEAD: Norms for Executive Functions tests in Portugal

All regression models for tests of executive functions were significant and accounted for $52-62 \%$ of the variance in M-WCST scores, and $37-68 \%$ of the variance in Stroop test scores. Performance on both the M-WCST and Stroop was related to age, although the direction of this relationship varied depending on the subtest modeled. Quadratic age effects were noted for M-WCST Categories, Stroop Color, and Stroop Word, as well as linear negative relationship for Stroop Word-Color score and Interference index, such that performance on all these tests worsened as age increased. Results for M-WCST Perseverative and Total errors were consistent, in which a positive curvilinear relationship with age was noted, also indicating worsening performance with increasing age.

Results are in line with prior studies that show decreasing ability in executive functions with advancing age (e.g., Fjell, Sneve, Grydeland, Storsve, \& Walhoved, 2016; Lezak et al., 2012; Princiotta, DeVries, \& Goldstein, 2014; Reuter-Lorenz, Festini, \& Jantz, 2016), being working memory, inhibition, planning, and cognitive flexibility the most affected EF processes (e.g., Amiéva, Phillips, \& Della Sala, 2003; Kirova, Bays, \& Lagalwar, 2015). Performance on the M-WCST has been reported to be associated both with age and education in the same direction as found in this study (del Pino, Peña, Ibarretxe-Bilbao, Schretlen, \& Ojeda, 2016; Lineweaver et al., 1999; Nakayama, Osawa, \& Maruyama, 1990; Zubicaray, Smith, Chalk, \& Semple, 1998), with similar findings for the Stroop test (for a review see Strauss et al., 2006).

Education appeared to act as a protective factor for all executive subtests, except for Stroop interference, in which it had no effect. Education improved performance curvilinearly on M-WCST Categories, Perseverative errors, Total errors, and Stroop Word, and linearly on Stroop Color and Word-Color. This is consistent with prior studies that showed improved executive functions with higher levels of education 
RUNNING HEAD: Norms for Executive Functions tests in Portugal

(Llinas-Regla, Vilalta-Franch, Lopez-Pousa, Calvo-Perxas, \& Garre-Olmo, 2013;

Moreira et al., 2014; Moreira et al., 2019; Pavão Martins, Maruta, Freitas, \& Mares,

2013). Higher education levels appear to contribute to cognitive reserve, behaving as a neuroprotector factor on the decline associated with healthy aging in EF (Roldán-Tapia, Cánovas, León, \& García-Garcia, 2017; Thow et al., 2018).

The only sex effect noted on executive functions tests was for Stroop WordColor, in which an interaction with age was noted. Sex effects on the M-WCST are generally not supported in the literature (Caffarra, Vezzadini, Dieci, Zonato, \& Venneri, 2004; del Pino et al., 2016; Obonsawin et al., 1999), with limited exceptions (ArangoLasprilla et al., 2015c; Lineweaver et al., 1999). Sex differences in Stroop performance, however, have some limited support in the literature, with women showing better performance on some tasks (Llinas-Regla et al., 2013; Strauss et al., 2006), although results are not always consistent (Brugnolo et al., 2016).

Regarding the assessment of attention, all models were significant and accounted for $71-78 \%$ of the variance of TMT scores, $79 \%$ of SDMT scores, and $41 \%$ of BTA scores. The effect of sociodemographic variables on the performance was grossly similar to that obtained for the EF tests. While advancing age was associated with worsening performance, higher levels of education were associated with better performance on all measures.

No sex effects were observed in the models. Again, results are generally consistent with prior studies, which show similar associations with age and education in the TMT (Arango-Lasprilla, et al., 2015a; Cavaco et al., 2013; Hamdan \& Hamdan, 2010; Pavão Martins et al., 2013), the SDMT (Arango-Lasprilla et al., 2015a; Benedict, Morrow, Weinstock-Guttman, Cookfair, \& Schretlen, 2010), and the BTA (Rivera et al., 2015a). Sex effects on the TMT have been found in studies with Portuguese 
RUNNING HEAD: Norms for Executive Functions tests in Portugal

samples, showing better performance for men (Cavaco et al., 2013; Pavão Martins et al., 2013), although findings have not been consistent throughout the literature (Tombaugh, 2004). For the SDMT, some studies have not found sex differences (Sheridan et al., 2006; Waldmann, Dickson, Monahan, \& Kazelskis, 1992), while others found small effect sizes, with women outperforming men (Laux \& Lane, 1985; Yeudall, Fromm, Reddon, \& Stefanyk, 1986). On the BTA, there is also some evidence that women perform better than men (Strauss et al., 2006), although this finding has not been consistent (Rivera et al., 2015a).

Age and education were consistent predictors across all tests modeled, with mostly curvilinear relationships. To note, on several measures the decline in performance started or accelerated after 35-45 years of age, denoting the quadratic effects in the model. The M-WCST total errors, Stroop word, Stroop color, TMT, and BTA all displayed this trend. Additionally, in M-WCST Categories, M-WCST Perseverative errors, and TMT, education did not have an impact on performance after 15 years of schooling.

By providing comprehensive norms for multiple comprehensive neuropsychological tests of EFs and attention, the current study is expected to contribute significantly to neuropsychological practice in Portugal. Having adjusted and updated normative data for Portuguese population is highly needed due to the potential biases of using norms from other regions to interpret raw scores. Let's suppose, for example, that we need a percentile score for a Portuguese woman who is 35 years old, has 10 years of education and scored 30 on TMT-A and 60 on TMT-B. Based on normative data from Italy (Siciliano et al., 2019), Czechia (Bezdicek et al., 2012), and Spain (Tamayo et al., 2012), this person would have obtained an adjusted z score of $0.385\left(35^{\text {th }}\right.$ percentile $),-0.181\left(43^{\text {rd }}\right.$ percentile $)$ and scaled score of $8\left(19^{\text {th }}\right.$ to $28^{\text {th }}$ 
RUNNING HEAD: Norms for Executive Functions tests in Portugal

percentile) respectively for TMT-A. For TMT-B, this person would have obtained an adjusted $z$ score of $0.297\left(62^{\text {nd }}\right.$ percentile $), 0.362\left(64^{\text {th }}\right.$ percentile $)$ and scaled score of 10 $\left(41^{\text {st }}\right.$ to $59^{\text {th }}$ percentile). Using the norms generated in this study, this person would have obtained an adjusted $z$ score of $-0.424\left(66^{\text {th }}\right.$ percentile $)$ for TMT-A and z score of -0.606 ( $73^{\text {rd }}$ percentile) for TMT-B.

In addition to making this information available, this study presents several advantages over prior work in this area, which was already limited in scope. Cavaco et al. (2013) conducted a normative study for the TMT in a Portuguese population with a large sample size, but none of the other tests examined here were part of that effort. Pavão Martins et al. (2013) conducted a study examining the effect of age and education on performance in EFs, but only the TMT and Stroop were considered, and the age range was restricted to adults over 50 years old. Fernandes (2012) published normative data for the Stroop test a sample of 290 Portuguese adults between 25 and 80 years old that are available in tables on the manual of the test.

Although regression-based norms have previously been obtained for one of the tests considered in this study (TMT; Cavaco et al., 2013), none using this methodology were available for the other four tests examined here. Furthermore, another strength of this study is both the consideration of possible multicollinearity between variables, as well as the investigation into quadratic relationships between predictors and performance, which revealed curvilinear relationships in 9 of the 11 models analyzed. Another advantage presented by this study is the simultaneous administration of the tests, which allows for inter-test comparisons with greater accuracy in a clinical setting as they were co-normed.

There is no reason to suspect significant regional variances, but while the northern region is overrepresented (i.e., Porto district), other regions of the country are 
RUNNING HEAD: Norms for Executive Functions tests in Portugal

underrepresented. Additionally, participants with no formal education were not included in the sample, so the norms should be interpreted with caution when used with such population. Also, subjects with a neurological and/or psychiatric condition were excluded from the study. Future efforts should include developing data for populations with neurological and/or psychiatric disorders.

The results of this study should interpret in light of some limitations. 1) The majority of participants of the study came from urban areas; future studies should include participants from rural areas of the country. 2) The inclusion and exclusion criteria of the study related to history of psychiatry and neurological conditions were based on participants self-report. 3) The level of bilingualism was not measured, and this is important because some studies have shown that bilingualism could affect cognitive performance. Future studies should include this variable and test it influence. 4) The neuropsychological test was normed in European Portuguese population and the results shouldn't apply to other Portuguese population outside Portugal (i.e. Brazil).

In sum, this is the first study to develop regression-based norms for an adult Portuguese sample for five simultaneously administered tests of EFs and attention. This co-norming approach is likely to yield greater precision in inter-test comparisons. In addition to providing new normative information, this study offers a calculator to be used by the clinician, which is likely to reduce errors that can arise when utilizing normative tables. To the best of the authors' knowledge, the current study is the most comprehensive norming effort for these tests in a Portuguese population. 
RUNNING HEAD: Norms for Executive Functions tests in Portugal

\section{Acknowledgments}

\section{Disclosure of interest}

The authors report no conflict of interest.

\section{Funding sources of financial support}

This work was supported by the Faculty of Psychology and Educational Sciences of the University of Porto, Portugal (FPCEUP). The Counselling Neuropsychology Unit of the FPCEUP; The Laboratory of Neuropsychophysiology of the FPCEUP; and the Centre of Psychology of the University of Porto, Porto, Portugal.. 
RUNNING HEAD: Norms for Executive Functions tests in Portugal

\section{References}

Aiken, L. S., West, S. G., \& Reno, R. R. (1991) Multiple regression: Testing and interpreting interactions. Newbury Park, Calif: Sage Publications.

Amiéva, H., Lafont, S., Rouch-Leroyer, I., Rainville, C., Dartigues, J. F., Orgogozo, J. M., \& Fabrigoule, C. (2004) Evidencing inhibitory deficits in Alzheimer Disease through interference effects and shifting disabilities in Stroop Test. Arch. Clin. Neuropsychol. 19, 791-803. doi: 10.1016/j.acn.2003.09.006

Amiéva, H., Phillips, L., \& Della Sala, S. (2003) Behavioural dysexecutive symptoms in normal aging. Brain Cognition, 53(2), 129-32. https://doi.org/10.1016/s02782626(03)00094-0 PMID: 14607132

Arango-Lasprilla, J. C., Rivera, D., Aguayo, A., Rodríguez, W., Garza, M. T., Saracho, C. P., ... \& Perrin, P. B. (2015a) Trail Making Test: Normative data for the Latin American Spanish speaking adult population. NeuroRehabilitation, 37(4), 639-661. https://doi.org/10.3233/NRE-151284

Arango-Lasprilla, J. C., Rivera, D., Longoni, M., Saracho, C. P. P., Garza, M. T. T., Aliaga, A., .. \& \& Perrin, P. B. (2015b) Symbol Digit Modalities Test: Normative data for the Latin American Spanish speaking adult population. NeuroRehabilitation, 37(4), 639-661. https://doi.org/10.3233/NRE-151284

Arango-Lasprilla, J. C., Rivera, D., Longoni, M., Saracho, C. P., Garza, M. T., Aliaga, A., ... \& Perrin, P. B. (2015c) Modified Wisconsin Card Sorting Test (M-WCST): Normative data for the Latin American Spanish speaking adult population. NeuroRehabilitation, 37(4), 563-590. https://doi.org/10.3233/NRE-151280

Army Individual Test Battery (1944) Manual of Directions and Scoring. Washington, DC: War Department, Adjutant General's Office.Baddeley, A. D. (1996). Exploring the central executive. The Quarterly Journal of Experimental Psychology Section A, 49(1), 5-28. https://doi.org/10.1080/713755608 
RUNNING HEAD: Norms for Executive Functions tests in Portugal

Baddeley, A. D. (1998) The central executive: A concept and some misconceptions. Journal of the International Neuropsychological Society, 4(5), 523-526.

Benedict, R. H. B., Morrow, S. A., Weinstock-Guttman, B., Cookfair, D., \& Schretlen, D. J. (2010) Cognitive reserve moderates decline in information processing speed in multiple sclerosis patients. Journal of the International Neuropsychological Society, 16(5), 829-835. https://doi.org/10.1017/S1355617710000688

Bezdicek, O., Motak, L., Axelrod, B. N., Preiss, M., Nikolai, T., Vyhnalek, M., ... \& Ruzicka, E. (2012). Czech version of the Trail Making Test: Normative data and clinical utility. Archives of Clinical Neuropsychology, 27(8), 906-914.

Binetti, G., Magni, E., Padovani, A., Cappa, S. F., Bianchetti, A., \& Trabucchi, M. (1996) Executive dysfunction in early Alzheimer's disease. Journal of Neurology, Neurosurgery \& Psychiatry, 60(1), 91-93. https://doi.org/10.1136/jnnp.60.1.91

Brown, E. C., Casey, A., Fisch, R. I., \& Neuringer, C. (1958) Trail Making Test as a screening device for the detection of brain damage. Journal of Consulting Psychology, 22(6), 469-474. http://dx.doi.org/10.1037/h0039980

Brugnolo, A., De Carli, F., Accardo, J., Amore, M., Bosia, L. E., Bruzzaniti, C., ... \& Girtler, N. (2016) An updated Italian normative dataset for the Stroop color word test (SCWT). Neurological Sciences, 37(3), 365-372. https://doi.org/10.1007/s10072-015-2428-2

Burzynska, A. Z., Nagel, I. E., Preuschhof, C., Gluth, S., Bäckman, L., Li, S. C., ... \& Heekeren H. R. (2012) Cortical thickness is linked to executive functioning in adulthood and aging. Hum. Brain Mapp. 33, 1607-1620. doi: 10.1002/hbm.21311

Caeyenberghs, K., Leemans, A., Leunissen, I., Gooijers, J., Michiels, K., Sunaert, S., \& Swinnen, S. (2014) Altered structural networks and executive deficits in traumatic 
RUNNING HEAD: Norms for Executive Functions tests in Portugal

brain injury patients. Brain Struct. Funct. 219, 193-209. doi: 10.1007/s00429-0120494-2

Caffarra, P., Vezzadini, G., Dieci, F., Zonato, F., \& Venneri, A. (2004) Modified Card Sorting Test: Normative Data. Journal of Clinical and Experimental Neuropsychology (Neuropsychology, Development and Cognition: Section A), 26(2), 246-250. https://doi.org/10.1076/jcen.26.2.246.28087

Caixeta, L., Soares, V. L., Vieira, R. T., Soares, C. D., Caixeta, V., Ferreira, S. B., \& Aversi-Ferreira, T. A. (2017). Executive function is selectively impaired in old age bipolar depression. Frontiers in psychology, 8, 194.

Carter, J. D., Bizzell, J., Kim, C., Bellion, C., Carpenter, K. L. H., Dichter, G., \& Belger, A. (2010) Attention deficits in schizophrenia - Preliminary evidence of dissociable transient and sustained deficits. Schizophrenia Research, 122(1-3),104-112. https://doi.org/10.1016/j.schres.2010.03.019

Cavaco, S., Gonçalves, A., Pinto, C., Almeida, E., Gomes, F., Moreira, I., ... \& TeixeiraPinto, A. (2013) Trail making test: Regression-based norms for the portuguese population. Archives of Clinical Neuropsychology, 28(2), 189-198. https://doi.org/10.1093/arclin/acs115

Chan, R. C. K. (2000) Attentional deficits in patients with closed head injury: A further study to the discriminative validity of the test of everyday attention. Brain Injury, 14(3), 227-236. https://doi.org/10.1080/026990500120709

Cicerone, K. D., \& Giacino, J. T. (1992) Remediation of Executive Function Deficits after Traumatic Brain Injury. NeuroRehabilitation, 2(3), 12-22. https://doi.org/10.3233/NRE-1992-2304

del Pino, R., Peña, J., Ibarretxe-Bilbao, N., Schretlen, D. J., \& Ojeda, N. (2016) Modified Wisconsin Card Sorting Test: standardization and norms of the test for a population 
RUNNING HEAD: Norms for Executive Functions tests in Portugal

sample in Spain. Revista de Neurologia, 62(5), 193-202. Retrieved from http://www.ncbi.nlm.nih.gov/pubmed/26916322

Dikmen, S. S., Heaton, R. K., Grant, I., \& Temkin, N. R. (1999) Test-retest reliability and practice effects of Expanded Halstead-Reitan Neuropsychological Test Battery. Journal of the International Neuropsychological Society, 5(4), 346-356. https://doi.org/10.1017/S1355617799544056

Dirnberger, G., \& Jahanshahi, M. (2013) Executive dysfunction in Parkinson's disease: a review. J. Neuropsychol. 7, 193-224. doi: 10.1111/jnp.12028

Dirnberger, G., Fuller, R., Frith, C., \& Jahanshahi, M. (2014) Neural correlates of executive dysfunction in schizophrenia: Failure to modulate brain activity with task demands. $\quad$ NeuroReport, 25(16), 1308-1315. https://doi.org/10.1097/WNR.0000000000000264

Fernandes, S. (2012) Stroop - Teste de Cores e Palavras: Manual da adaptação Portuguesa. Lisboa: CEGOC.

Filipe, M. G., Frota, S., \& Vicente, S. G. (2019). Executive Functions and Prosodic Abilities in Children with High-Functioning Autism. In MacPherson, S. E., Gillebert, C. R., Robinson, G. A., Vallesi, A., (Eds.), Intra and inter-Individual Variability of Executive Functions: Determinant and Modulating Factors in Healthy and Pathological Conditions (pp. 78-87). Lausanne: Frontiers Media. ISBN: 978-2-88945-837-0 /doi: 10.3389/978-2-88945-837-0

Fiorentino, N., Gleichgerrcht, E., Roca, M., Cetkovich, M., Manes, F., \& Torralva, T. (2013) The INECO Frontal Screening tool diferentiates behavioral variantfrontotemporal dementia (by-FTD) for major depression. Dement. Neuropsychol. 7, 33-39. doi: 10.1590/S1980-57642013DN701 00006 
RUNNING HEAD: Norms for Executive Functions tests in Portugal

Firbank, M., Kobeleva, X., Cherry, G., Killen, A., Gallagher, P., Burn, D. J., ... \& Taylor, J. P. (2016) Neural correlates of attention-executive dysfunction in lewy body dementia and Alzheimer's disease. Human Brain Mapping, 37, 1254-1270. https://doi.org/10.1002/hbm.23100

Fjell, A. M., Sneve, M. H., Grydeland, H., Storsve, A. B., \& Walhovd, K. B. (2016) The disconnected brain and executive function decline in aging. Cerebral cortex, $27(3), 2303-2317$.

Folstein, M. F., Folstein, S. E., \& McHugh, P. R. (1975) “Mini-mental state”: a practical method for grading the cognitive state of patients for the clinician. Journal of psychiatric research, 12(3), 189-198.

Gavilán, J. M., \& García-Albea, J. E. (2015) Executive dysfunction in schizophrenia and its association with mentalizing abilities. Revista de Psiquiatría y Salud Mental (English Edition), 8(3), 119-129. https://doi.org/10.1016/j.rpsmen.2015.05.003

Golden, C., \& Freshwater, S. M. (2002) Stroop Color and Word Test. Odessa, FL: Psychological Assessment Resources.

Goldstein, S., Naglieri, J. A., Princiotta, D., \& Otero, T. M. (2014) Introduction: A History of Executive Functioning as a Theoretical and Clinical Construct. In Goldstein S., \& Naglieri J. A. (Eds.), Handbook of Executive Functioning (pp. 312). New York: Springer.

Groeneweg, M., Moerland, W., Quero, J. C., Hop, W. C. J., Krabbe, P. F., \& Schalm, S. W. (2000). Screening of subclinical hepatic encephalopathy. Journal of Hepatology, 32(5), 748-753 https://doi.org/10.1016/S0168-8278(00)80243-3

Hamdan, A. C., \& Hamdan, E. M. L. R. (2010) Effects of age and education level on the Trail Making Test in a healthy Brazilian sample. Psychology \& Neuroscience, 2(2), 199-203. https://doi.org/10.3922/j.psns.2009.2.012 
RUNNING HEAD: Norms for Executive Functions tests in Portugal

IBM Corp. (2015). IBM SPSS Statistics for Windows, Version 23.0. Armonk, NY: IBM Corp.

Jorm, A. F., Anstey, K. J., Christensen, H., \& Rodgers, B. (2004) Gender differences in cognitive abilities: The mediating role of health state and health habits. Intelligence, 32(1), 7-23. https://doi.org/10.1016/j.intell.2003.08.001

Jurado, M. B., \& Rosselli, M. (2007) The Elusive Nature of Executive Functions: A Review of our Current Understanding. Neuropsychology Review, 17(3), 213-233. https://doi.org/10.1007/s11065-007-9040-Z

Kingdon, D., Cardoso, C., \& McGrath, J. J. (2016) Research Review: Executive function deficits in fetal alcohol spectrum disorders and attention-deficit/hyperactivity disorder - a meta-analysis. Journal of Child Psychology and Psychiatry and Allied Disciplines, 57(2), 116-131. https://doi.org/10.1111/jcpp.12451

Kirova, A. M., Bays, R. B., \& Lagalwar, S. (2015). Working memory and executive function decline across normal aging, mild cognitive impairment, and Alzheimer's disease. BioMed research international, 2015.

Kroenke, K., Spitzer, R. L., \& Williams, J. B. (2001) The PHQ-9. Journal of General Internal Medicine, 16(9), 606-613.

Kutner, M. H., Nachtsheim, C. J., Neter, J., \& Li, W. (2005) Applied linear statistical models (5th ed.). New York: McGraw Hill.

Laux, L. F., \& Lane, D. M. (1985) Information processing components of substitution test performance. Intelligence, 9(2), 111-136. https://doi.org/10.1016/01602896(85)90012-1

Levine, J., Miller, E. N., Becker, J. T., Selnes, O. A., \& Cohen, B. A. (2004) Normative data for determining significance of test-retest differences on eight common 
RUNNING HEAD: Norms for Executive Functions tests in Portugal

neuropsychological instruments. Clinical Neuropsychologis, 18(3), 373-384, https://doi.org/10.1080/1385404049052420

Lezak, M. D., Howieson, D. B., Bigler, E. D., \& Tranel, D. (2012) Neuropsychological Assessment, 5th Edn. London: Oxford University Press.

Lima, C. F., Meireles, L. P., Fonseca, R., Castro, S. L., \& Garret, C. (2008) The Frontal Assessment Battery (FAB) in Parkinson's disease and correlations with formal measures of executive functioning. J. Neurol. 255, 1756-1761. doi: $10.1007 / \mathrm{s} 00415-008-0024-6$

Lineweaver, T. T., Bondi, M. W., Thomas, R. G., \& Salmon, D. P. (1999) A Normative Study of Nelson's (1976) Modified Version of the Wisconsin Card Sorting Test in Healthy Older Adults. The Clinical Neuropsychologist, 13(3), 328-347. https://doi.org/10.1076/clin.13.3.328.1745

Llinas-Regla, J., Vilalta-Franch, J., Lopez-Pousa, S., Calvo-Perxas, L., \& Garre-Olmo, J.

(2013) Demographically Adjusted Norms for Catalan Older Adultson the Stroop Color and Word Test. Archives of Clinical Neuropsychology, 28(3), 282-296. https://doi.org/10.1093/arclin/act003

Mahoney, F.I., \& Barthel, D. (1965) Functional evaluation: the Barthel Index. Maryland State Medical Journal, 14, 56-61.

Margari, L., Craig, F., Margari, F., Legrottaglie, A., Palumbi, R., \& De Giambattista, C. (2016) A review of executive function deficits in autism spectrum disorder and attention-deficit/hyperactivity disorder. Neuropsychiatric Disease and Treatment, 1191. https://doi.org/10.2147/NDT.S104620

McDonald, B. C., Flashman, L. A., \& Saykin, A. J. (2002) Executive dysfunction following traumatic brain injury: neural substrates and treatment strategies. NeuroRehabilitation, 17(4), 333-344. 
RUNNING HEAD: Norms for Executive Functions tests in Portugal

Miller, M., \& Hinshaw, S. P. (2015) Attention-Deficit/Hyperactivity Disorder. In Encyclopedia of Mental Health: Second Edition. https://doi.org/10.1016/B978-0$12-397045-9.00229-9$

Mitrushina, M. N. (2005) Handbook of normative data for neuropsychological assessment. New York: Oxford University Press.

Moreira, H. S., Costa, A. S., Machado Á., Castro, S. L., Lima, C. F., \& Vicente, S. G. (2019) Distinguishing mild cognitive impairment from healthy aging and Alzheimer's Disease: The contribution of the INECO Frontal Screening (IFS). PLoS ONE 14(9): e0221873. https://doi.org/10.1371/journal. pone.0221873

Moreira, H., Lima, C. F., \& Vicente, S. G. (2014) Examining executive dysfunction with the Institute of Cognitive Neurology (INECO) Frontal Screening (IFS): Normative values in a healthy sample and clinical utility in Alzheimer's disease. Journal of Alzheimer's Disease, 42, 261-273. doi: 10.3233/JAD-132348

Nagahama, Y., Okina, T., Suzuki, N., Matsuzaki, S., Yamauchi, H., Nabatame, H., \& Matsuda, M. (2003) Factor Structure of a Modified Version of the Wisconsin Card Sorting Test: An Analysis of Executive Deficit in Alzheimer's Disease and Mild Cognitive Impairment. Dementia and Geriatric Cognitive Disorders, 16(2), 103112. https://doi.org/10.1159/000070683

Nakayama, H., Osawa, M., \& Maruyama, S. (1990). Aging effect on frontal lobe function-evaluation by the new modified Wisconsin Card Sorting Test. No to shinkei $=$ Brain and nerve, 42(8), 765-771.

Nelson, H. E. (1976) A modified card sorting test sensitive to frontal lobe defects. Cortex, $12(4), 313-324$.

Obonsawin, M. C., Crawford, J. R., Page, J., Chalmers, P., Low, G., \& Marsh, P. (1999) Performance on the modified card sorting test by normal, healthy individuals: 
RUNNING HEAD: Norms for Executive Functions tests in Portugal

Relationship to general intellectual ability and demographic variables. British $\begin{array}{llll}\text { Journal of } & \text { Clinical }\end{array}$ https://doi.org/10.1348/014466599162647

Olgiati, E., Russell, C., Soto, D., \& Malhotra, P. (2016) Motivation and attention following hemispheric stroke. In Progress in Brain Research. https://doi.org/10.1016/bs.pbr.2016.06.011

Packwood, S., Hodgetts, H. M., \& Tremblay, S. (2011) A multiperspective approach to the conceptualization of executive functions. Journal of Clinical and Experimental Neuropsychology, 33 (4), 456-470. doi: $10.1080 / 13803395.2010 .533157$

Papagno, C., \& Trojano, L. (2018) Cognitive and behavioral disorders in Parkinson's disease: an update. I: cognitive impairments. Neurological Sciences, 39 (2), 215223. https://doi.org/10.1007/s10072-017-3154-8

Pavão Martins, I., Maruta, C., Freitas, V., \& Mares, I. (2013) Executive performance in older portuguese adults with low education. Clinical Neuropsychologist, 27(3), 410425. https://doi.org/10.1080/13854046.2012.748094

Petersen, S. E., \& Posner, M. I. (2012) The attention system of the human brain: 20 years after. Annual Review of Neuroscience, 35, 73-89. https://doi.org/10.1146/annurevneuro-062111-150525

Pohjasvaara, T., Leskelä, M., Vataja, R., Kalska, H., Ylikoski, R., Hietanen, M., ... \& Erkinjuntti, T. (2002). Post-stroke depression, executive dysfunction and functional outcome. European Journal of Neurology, 9(3), 269-275. https://doi.org/10.1046/j.1468-1331.2002.00396.x 
RUNNING HEAD: Norms for Executive Functions tests in Portugal

Princiotta, D., DeVries, M., \& Goldstein, S. (2014). Executive Functioning as a Mediator of Age-Related Cognitive Decline in Adults. In Goldstein S., \& Naglieri J. A. (Eds.), Handbook of Executive Functioning (pp. 143-155). New York: Springer.

R Development Core Team (2013). R: A language and environment for statistical computing. Vienna, Austria: R Foundation for Statistical Computing. Retrieved from http://www.R-project.org/

Reitan, R. M. (1958). The validity of the Trail Making Test as an indicator of organic brain damage. Perceptual and Motor Skills, 8, 271-276.

Reitan, R. M., \& Wolfson, D. (1995). Category Test and Trail Making Test as Measures of Frontal Lobe Functions. The Clinical Neuropsychologist, 9, 50-56. https://doi.org/10.1080/13854049508402057

Reuter-Lorenz PA, Festini SB, \& Jantz TK. Executive Functions and Neurocognitive Aging. In: Schaie KW, Willis SL, editors. Handbook of the Psychology of Aging. Oxford: Elsevier; 2016. pp. 245-262. i[s-pi

Richardson, E. D., \& Marottoli, R. A. (1996). Education-Specific normative data on common neuropsy-chological indices for individuals older than 75 Years. The Clinical Neuropsychologist, $\quad$ 10(4), 375-381. https://doi.org/10.1080/13854049608406698

Rivera, D., Olabarrieta-Landa, L., Van der Elst, W., Gonzalez, I., Rodríguez-Agudelo, Y., Aguayo Arelis, A., ... \& Arango-Lasprilla, J. C. (2019). Normative data for verbal fluency in healthy Latin American adults: Letter M, and fruits and occupations categories. Neuropsychology, 33(3), 287-300.

Rivera, D., Perrin, P. B., Stevens, L. F., Garza, M. T., Weil, C., Saracho, C. P., ...\& Arango-Lasprilla, J. C. (2015). Brief Test of Attention: Normative data for the 
RUNNING HEAD: Norms for Executive Functions tests in Portugal

Latin American Spanish speaking adult population. NeuroRehabilitation, 37(4), 663-676. https://doi.org/10.3233/NRE-151283

Rivera, D., Perrin, P. B., Stevens, L. F., Garza, M. T., Weil, C., Saracho, C. P., ... \& Arango-Lasprilla, J. C. (2015). Stroop Color-Word Interference Test: Normative data for the Latin American Spanish speaking adult population. NeuroRehabilitation, 37(4), 591-624. https://doi.org/10.3233/NRE-151281

Robinson, H., Calamia, M., Glascher, J., Bruss, J., \& Tranel, D. (2014). Neuroanatomical correlates of executive functions: a neuropsychological approach using the EXAMINER battery. J. Int. Neuropsychol. Soc. 20, 52-63. doi: $10.1017 / \mathrm{S} 135561771300060 \mathrm{X}$

Roldán-Tapia, M. D, Cánovas, R., León, I., \& García-Garcia, J. (2017). Cognitive Vulnerability in Aging May Be Modulated by Education and Reserve in Healthy People. Frontiers Aging Neuroscience, 9, 1-9. doi. 10.3389/fnagi.2017.00340

Royan, J., Tombaugh, T. N., Rees, L., \& Francis, M. (2004). The Adjusting-Paced Serial Addition Test (Adjusting-PSAT): Thresholds for speed of information processing as a function of stimulus modality and problem complexity. Archives of Clinical Neuropsychology, 19(1), 131-143. https://doi.org/10.1016/S08876177(02)00216-0

Sachdev, P. S., Blacker, D., Blazer, D. G., Ganguli, M., Jeste, D. V., Paulsen, J. S., \& Petersen, R. C. (2014). Classifyng neurocognitive disorders: the DSM-5 approach. Nature Reviews Neurology, 10, 634-642. doi:10.1038/nrneurol.2014.181

Schretlen, D. J. (1997). Brief test of attention professional manual. Odessa, FL: Psychological Assesment Resources.

Schretlen, D. J. (2010). M-WCST (Modified Wisconsin Card Sorting Test). Odessa, FL: Psychological Assessment Resources. 
RUNNING HEAD: Norms for Executive Functions tests in Portugal

Schretlen, D., Bobholz, J., \& Brandt, J. (1996). Development and psychometric properties of the brief test of attention. Clinical Neuropsychologist, 10(1), 80-89.

Shah, S. A., Goldin, Y., Conte, M. M., Goldfine, A. M., Mohamadpour, M., Fidali, B. C., ... \& Schiff, N. D. (2017). Executive attention deficits after traumatic brain injury reflect impaired recruitment of resources. NeuroImage: Clinical, 14, 233-241. https://doi.org/10.1016/j.nicl.2017.01.010

Sheridan, L. K., Fitzgerald, H. E., Adams, K. M., Nigg, J. T., Martel, M. M., Puttler, L. I., ... \& Zucker, R. A. (2006). Normative Symbol Digit Modalities Test performance in a community-based sample. Archives of Clinical Neuropsychology, 21(1), 23-28. https://doi.org/10.1016/j.acn.2005.07.003

Shoqeirat, M. A., Mayes, A., MacDonald, C., Meudell, P., \& Pickering, A. (1990). Performance on tests sensitive to frontal lobe lesions by patients with organic amnesia: Leng \& Parkin revisited. British Journal of Clinical Psychology, 29(4), 401-408. https://doi.org/10.1111/j.2044-8260.1990.tb00903.x

Siciliano, M., Chiorri, C., Battini, V., Sant'Elia, V., Altieri, M., Trojano, L., \& Santangelo, G. (2019). Regression-based normative data and equivalent scores for Trail Making Test (TMT): An updated Italian normative study. Neurological Sciences, 40(3), 469-477.

Slachevsky, A., Villapando, J. M., Sarazin, M., Hahn-Barma, V., Pillon, B., \& Dubois, B. (2004). Frontal assessment battery and differential diagnosis of frontotemporal dementia and Alzheimer Disease. Arch. Neurol. 61, 1104-1107. doi: 10.1001/archneur.61.7.1104

Smith, A. (1982). Symbol Digits Modalities Test. Los Angeles: Western Psychological Services. 
RUNNING HEAD: Norms for Executive Functions tests in Portugal

Smith, A. (1991). Symbol Digit Modalities Test (Western Psychological Services, Ed.). Los Angeles, CA: Western Psychological Services.

Sohlberg, M. M., \& Mateer, C. A. (2002). Cognitive rehabilitation. An integrative neuropsychological approach. In Mycological Research (Vol. 106). Retrieved from papers2://publication/uuid/542C35F2-3BA9-4821-9508-1E3E60550FAD

Spreen, O., \& Strauss, E. (1998). A compendium of neurological tests: administration, norms, and commentary.

Stokholm, J., Vogel, A., Gade, A., \& Waldemar, G. (2005). The executive interview as a screening test for executive dysfunction in patients with mild dementia. Journal of the American Geriatrics Society. https://doi.org/10.1111/j.1532$5415.2005 .53470 . x$

Strauss, E., Sherman, E. M. S., \& Spreen, O. (2006). A compendium of neuropsychological tests: Administration, norms, and commentary (3rd ed.). New York, NY, US: Oxford University Press.

Stroop, J. R. (1935). Studies of interference in serial verbal reactions. Journal of Experimental Psychology, 18(6), 643-662. https://doi.org/10.1037/h0054651

Stuss, D. T. (2011). Functions of the frontal lobes: Relation to executive functions. Journal of the International Neuropsychological Society, 17, 759-765. https://doi.org/10.1017/S1355617711000695

Swanberg, M. M., Tractenberg, R. E., Mohs, R., Thal, L. J., \& Cummings, J. L. (2004). Executive dysfunction in Alzheimer disease. Archives of Neurology, 61(4), 556560. https://doi.org/10.1001/archneur.61.4.556\n61/4/556 [pii]

Tamayo, F., Casals-Coll, M., Sánchez-Benavides, G., Quintana, M., Manero, R. M., Rognoni, T., ... \& Peña-Casanova, J. (2012). Estudios normativos españoles en población adulta joven (Proyecto NEURONORMA jóvenes): normas para las 
RUNNING HEAD: Norms for Executive Functions tests in Portugal

pruebas span verbal, span visuoespacial, Letter-Number Sequencing, Trail Making Test y Symbol Digit Modalities Test. Neurología, 27(6), 319-329.

Thow, M. E., Summers, M. J., Sauders, N. L., Summers, J. J., Ritchie, K., \& Vickers, J. C. (2018). Further education improves cognitive reserve and triggers improvement in selective cognitive functions in older adults: The Tasmanian Healthy Brain Project. Alzheimer's \& Dementia: Diagnosis, Assessment \& Disease Monitoring, 10, 22-30. http://dx.doi.org/10.1016/j.dadm.2017.08.004

Tombaugh, T. N. (2004). Trail Making Test A and B: Normative data stratified by age and education. Archives of Clinical Neuropsychology, 19(2), 203-214. https://doi.org/10.1016/S0887-6177(03)00039-8

Tramontana, M. G., Cowan, R. L., Zald, D., Prokop, J. W., \& Guillamondegui, O. (2014). Traumatic brain injury-related attention deficits: Treatment outcomes with lisdexamfetamine dimesylate (Vyvanse). Brain Injury, 28(11), 1461-1472, https://doi.org/10.3109/02699052.2014.930179

Uchiyama, C. L., D’Elia, L. F., Dellinger, A. M., Selnes, O. A., Becker, J. T., Wesch, J. E., ... \& Miller, E. N. (1994). Longitudinal comparison of alternate versions of the symbol digit modalities test: Issues of form comparability and moderating demographic variables. Clinical Neuropsychologist, 8(2) 209-218. https://doi.org/10.1080/13854049408401558

Van Breukelen, G. J., \& Vlaeyen, J. W. (2005). Norming clinical questionnaires with multiple regression: the Pain Cognition List. Psychological assessment, 17(3), 336-344.

Van den Broek, M. D., Bradshaw, C. M., \& Szabadi, E. (1993). Utility of the Modified Wisconsin Card Sorting Test in neuropsychological assessment. British Journal 
RUNNING HEAD: Norms for Executive Functions tests in Portugal

of Clinical Psychology, 32(3), 333-343. https://doi.org/10.1111/j.20448260.1993.tb01064.x

Van Der Elst, W., Van Boxtel, M. P., Van Breukelen, G. J., \& Jolles, J. (2006a). Normative data for the Animal, Profession and Letter M Naming verbal fluency tests for Dutch speaking participants and the effects of age, education, and sex. Journal of the International Neuropsychological Society, 12(01), 80-89.

Van der Elst, W., van Boxtel, M. P., van Breukelen, G. J., \& Jolles, J. (2006b). The Letter Digit Substitution Test: normative data for 1,858 healthy participants aged 24-81 from the Maastricht Aging Study (MAAS): influence of age, education, and sex. Journal of Clinical and Experimental Neuropsychology, 28(6), 998-1009.

Vataja, R., Pohjasvaara, T., Mantyla, R., Ylikoski, R., Leppavuori, A., Leskela, M., ... \& Erkinjuntti, T. (2003). MRI correlates of executive dysfunction in patients with ischaemic stroke. European Journal of Neurology, 10(6), 625-631. https://doi.org/10.1046/j.1468-1331.2003.00676.x

Waldmann, B. W., Dickson, A. L., Monahan, M. C., \& Kazelskis, R. (1992). The relationship between intellectual ability and adult performance on the trail making test and the symbol digit modalities test. Journal of Clinical Psychology. https://doi.org/10.1002/1097-4679(199205)48:3<360::AID-

JCLP2270480314>3.0.CO;2-P

Yeudall, L. T., Fromm, D., Reddon, J. R., \& Stefanyk, W. O. (1986). Normative data stratified by age and sex for 12 neuropsychological tests. Journal of Clinical Psychology. $\quad$ https://doi.org/10.1002/1097-4679(198611)42:6<918::AIDJCLP2270420617>3.0.CO;2-Y

Zgaljardic, D., Borod, J., Foldi, N., Mattis, P., Gordon, M., Feigin, A., \& Eidelberg, D. (2006). An examination of executive dysfunction associated with frontostriatal 
RUNNING HEAD: Norms for Executive Functions tests in Portugal

circuitry in Parkinson's disease. Journal of Clinical and Experimental Neuropsychology, $28(7)$ $1127-1144$. https://doi.org/10.1080/13803390500246910

Zubicaray, G. de, \& Ashton, R. (1996). Nelson's (1976) modified card sorting test: A review. The Clinical Neuropsychologist, 10(3), 245-254. https://doi.org/10.1080/13854049608406687

Zubicaray, G. I., Smith, G. A., Chalk, J. B., \& Semple, J. (1998). The Modified Card Sorting Test: Test-retest stability and relationships with demographic variables in a healthy older adult sample. British Journal of Clinical Psychology. https://doi.org/10.1111/j.2044-8260.1998.tb01403. 
RUNNING HEAD: Norms for Executive Functions tests in Portugal

Table 1. Demographic characteristics of the sample.

Table 2. Correlations between all scores and demographic variables.

Table 3. Final multiple linear regression models for M-WCST.

Table 4. Final multiple linear regression models for Stroop test.

Table 5. Final multiple linear regression models for TMT.

Table 6. Final multiple linear regression models for SDMT and BTA.

Table 7. Standard deviation (residual) for final multiple linear regression models.

Figure 1. Predicted mean scores as a function of age and education for the M-WCST Categories (A) and M-WCST Total Errors (B); age and sex interaction for the Stroop Word-Color (C). Predicted mean scores as a function of age and education for the TMTA (D), SDMT (E), and BTA (F). 
Table 1.

Demographic characteristics of the sample.

\begin{tabular}{cccccccc}
\hline & & \multicolumn{2}{c}{ Age } & \multicolumn{2}{c}{ Education } & \multicolumn{2}{c}{ Sex } \\
\cline { 3 - 8 } Age group & $\boldsymbol{n}_{\boldsymbol{i}}$ & $\boldsymbol{M}$ & $\boldsymbol{S D}$ & $\boldsymbol{M}$ & $\boldsymbol{S D}$ & Woman & Man \\
\hline $20 \pm 2$ year & 19 & 20.7 & 1.5 & 12.7 & 2.1 & 13 & 6 \\
\hline $25 \pm 2$ year & 56 & 24.5 & 1.3 & 15.3 & 2.1 & 37 & 19 \\
\hline $30 \pm 2$ year & 16 & 30.4 & 1.6 & 15.3 & 3.8 & 11 & 5 \\
\hline $35 \pm 2$ year & 11 & 34.8 & 1.7 & 13.6 & 4.7 & 4 & 7 \\
\hline $40 \pm 2$ year & 18 & 40.4 & 1.4 & 12.1 & 4.4 & 7 & 11 \\
\hline $45 \pm 2$ year & 13 & 44.7 & 1.5 & 11.4 & 5.5 & 6 & 7 \\
\hline $50 \pm 2$ year & 28 & 50.2 & 1.2 & 9.6 & 4.8 & 15 & 13 \\
\hline $55 \pm 2$ year & 11 & 54.9 & 1.8 & 11.2 & 4.8 & 9 & 2 \\
\hline $60 \pm 2$ year & 21 & 59.8 & 1.5 & 9.4 & 4.3 & 15 & 6 \\
\hline $65 \pm 2$ year & 28 & 65.4 & 1.3 & 7.2 & 4.0 & 20 & 8 \\
\hline $70 \pm 2$ year & 22 & 69.4 & 1.5 & 7.8 & 4.4 & 16 & 6 \\
\hline $75 \pm 2$ year & 26 & 75.0 & 1.6 & 5.7 & 3.6 & 14 & 12 \\
\hline $80 \pm 2$ year & 12 & 79.3 & 1.6 & 4.3 & 1.5 & 8 & 4 \\
\hline$>82$ & 19 & 87.0 & 3.0 & 4.6 & 2.2 & 13 & 6 \\
\hline Total & $\mathbf{3 0 0}$ & $\mathbf{5 0 . 4}$ & $\mathbf{2 1 . 2}$ & $\mathbf{1 0 . 4}$ & $\mathbf{5 . 2}$ & $\mathbf{1 8 8}$ & $\mathbf{1 1 2}$ \\
\hline
\end{tabular}

Note. $\mathrm{M}=$ Mean; $S D=$ Standard deviation 
Table 2.

Correlations between all scores and demographic variables.

\begin{tabular}{cccc}
\hline & Age & Education & Sex \\
\hline M-WCST Categories & $-.669^{* *}$ & $.679^{* *}$ & .004 \\
\hline M-WCST Perseverative errors & $.651^{* *}$ & $-.652^{* *}$ & -.006 \\
\hline M-WCST Total errors & $.675^{* *}$ & $-.698^{* *}$ & .010 \\
\hline Stroop Word & $-.698^{* *}$ & $.683^{* *}$ & .039 \\
\hline Stroop Color & $-.729^{* *}$ & $.636^{* *}$ & .027 \\
\hline Stroop Word-color & $-.800^{* *}$ & $.692^{* *}$ & .034 \\
\hline Stroop Interference & $-.610^{* *}$ & $.489^{* *}$ & .030 \\
\hline TMT-A & $.771^{* *}$ & $-.708^{* *}$ & -.05 \\
\hline TMT-B & $.775^{* *}$ & $-.747^{* *}$ & -.056 \\
\hline SDMT & $-.825^{* *}$ & $.785^{* *}$ & -.030 \\
\hline BTA & $-.542^{* *}$ & $.580^{* *}$ & -.028 \\
\hline
\end{tabular}

Note. ${ }^{* *}=p<0.001$ 
Table 3.

Final multiple linear regression models for M-WCST.

\begin{tabular}{|c|c|c|c|c|c|c|c|}
\hline Score & Variable & B & SE & $\beta$ & $t$ & Sig. & Adj. $R^{2}$ \\
\hline \multirow{5}{*}{$\begin{array}{l}\text { M-WCST } \\
\text { Categories }\end{array}$} & (Constant) & 5.391 & .121 & & 44.700 & $<.001$ & \multirow{5}{*}{.592} \\
\hline & Age & -.026 & .004 & -.306 & -5.761 & $<.001$ & \\
\hline & $\mathrm{Age}^{2}$ & -.001 & $1.8 \mathrm{E}-04$ & -.145 & -3.878 & $<.001$ & \\
\hline & Education & .162 & .018 & .471 & 8.873 & $<.001$ & \\
\hline & Education $^{2}$ & -.013 & .003 & -.188 & -4.842 & $<.001$ & \\
\hline \multirow{5}{*}{$\begin{array}{c}\text { M-WCST } \\
\text { Perseverative } \\
\text { errors }\end{array}$} & (Constant) & 1.846 & .428 & .000 & 4.315 & $<.001$ & \multirow{5}{*}{.592} \\
\hline & Age & .091 & .016 & .302 & 5.696 & $<.001$ & \\
\hline & $\mathrm{Age}^{2}$ & .004 & .001 & .227 & 6.064 & $<.001$ & \\
\hline & Education & -.535 & .065 & -.439 & -8.265 & $<.001$ & \\
\hline & Education $^{2}$ & .048 & .010 & .193 & 4.974 & $<.001$ & \\
\hline \multirow{5}{*}{$\begin{array}{c}\text { M-WCST Total } \\
\text { errors }\end{array}$} & (Constant) & 6.890 & .748 & & 9.212 & $<.001$ & \multirow{5}{*}{.621} \\
\hline & Age & .153 & .028 & .281 & 5.501 & $<.001$ & \\
\hline & $\mathrm{Age}^{2}$ & .004 & .001 & .133 & 3.689 & .003 & \\
\hline & Education & -1.131 & .113 & -.512 & -9.994 & $<.001$ & \\
\hline & Education $^{2}$ & .098 & .017 & .218 & 5.832 & $<.001$ & \\
\hline
\end{tabular}

Note. M-WCST $=$ Modified-Wisconsin Card Sorting Test 
Table 4.

Final multiple linear regression models for Stroop test.

\begin{tabular}{|c|c|c|c|c|c|c|c|}
\hline Score & Variable & B & SE & $\beta$ & $t$ & Sig. & $\begin{array}{c}\text { Adj. } \\
R^{2}\end{array}$ \\
\hline \multirow{5}{*}{$\begin{array}{l}\text { Stroop } \\
\text { Word }\end{array}$} & (Constant) & 93.084 & 1.375 & & 67.679 & $<.001$ & \multirow{5}{*}{.595} \\
\hline & Age & -.375 & .051 & -.387 & -7.322 & $<.001$ & \\
\hline & $\mathrm{Age}^{2}$ & -.008 & .002 & -.153 & -4.100 & $<.001$ & \\
\hline & Education & 1.610 & .208 & .409 & 7.734 & $<.001$ & \\
\hline & Education $^{2}$ & -.081 & .031 & -.101 & -2.621 & $<.001$ & \\
\hline \multirow{4}{*}{$\begin{array}{l}\text { Stroop } \\
\text { Color }\end{array}$} & (Constant) & 66.542 & .953 & & 69.829 & $<.001$ & \multirow{4}{*}{.588} \\
\hline & Age & -.428 & .040 & -.546 & -10.628 & $<.001$ & \\
\hline & $\mathrm{Age}^{2}$ & -.007 & .002 & -.166 & -4.439 & $<.001$ & \\
\hline & Education & .768 & .163 & .242 & 4.697 & $<.001$ & \\
\hline \multirow{5}{*}{$\begin{array}{c}\text { Stroop } \\
\text { Word-Color }\end{array}$} & (Constant) & 34.720 & .600 & & 57.868 & $<.001$ & \multirow{5}{*}{.683} \\
\hline & Age & -.364 & .037 & -.529 & -9.939 & $<.001$ & \\
\hline & Education & .812 & .128 & .291 & 6.326 & $<.001$ & \\
\hline & Sex & 1.178 & .990 & .039 & 1.190 & .235 & \\
\hline & Age X Sex & -.137 & .048 & -.116 & -2.877 & .004 & \\
\hline \multirow{2}{*}{$\begin{array}{c}\text { Stroop } \\
\text { Interference }\end{array}$} & (Constant) & -1.278 & .375 & & -3.406 & .001 & \multirow{2}{*}{.370} \\
\hline & Age & -.236 & .018 & -.610 & -13.301 & $<.001$ & \\
\hline
\end{tabular}


Table 5.

Final multiple linear regression models for TMT.

\begin{tabular}{|c|c|c|c|c|c|c|c|}
\hline Score & Variable & B & SE & $\beta$ & $t$ & Sig. & $\operatorname{Adj} . R^{2}$ \\
\hline \multirow{5}{*}{ TMT-A } & (Constant) & 39.705 & 1.495 & & 26.556 & $<.001$ & \multirow{5}{*}{.708} \\
\hline & Age & .588 & .056 & .474 & 10.552 & $<.001$ & \\
\hline & $\mathrm{Age}^{2}$ & .012 & .002 & .175 & 5.513 & $<.001$ & \\
\hline & Education & -1.900 & .226 & -.378 & -8.398 & $<.001$ & \\
\hline & Education $^{2}$ & .157 & .033 & .155 & 4.701 & $<.001$ & \\
\hline \multirow{5}{*}{ ТМТ-В } & (Constant) & 83.181 & 4.238 & & 19.625 & $<.001$ & \multirow{5}{*}{.776} \\
\hline & Age & 1.679 & .158 & .418 & 10.629 & $<.001$ & \\
\hline & $\mathrm{Age}^{2}$ & .053 & .006 & .236 & 8.507 & $<.001$ & \\
\hline & Education & -7.353 & .641 & -.451 & -11.464 & $<.001$ & \\
\hline & Education $^{2}$ & .583 & .095 & .177 & 6.142 & $<.001$ & \\
\hline
\end{tabular}

Note. TMT $=$ Trail Making Test 
Table 6.

Final multiple linear regression models for SDMT and BTA.

\begin{tabular}{|c|c|c|c|c|c|c|c|}
\hline Score & Variable & B & SE & $\beta$ & $t$ & Sig. & Adj. $R^{2}$ \\
\hline \multirow{5}{*}{ SDMT } & (Constant) & 44.398 & .895 & & 49.605 & $<.001$ & \multirow{5}{*}{.787} \\
\hline & Age & -0.431 & .033 & -.496 & -12.933 & $<.001$ & \\
\hline & Age2 & -0.004 & .001 & -.090 & -3.314 & .001 & \\
\hline & Education & 1.567 & .135 & .444 & 11.569 & $<.001$ & \\
\hline & Education2 & -0.077 & .020 & -.107 & -3.824 & $<.001$ & \\
\hline \multirow{5}{*}{ BTA } & (Constant) & 15.618 & .333 & & 46.874 & $<.001$ & \multirow{5}{*}{.408} \\
\hline & Age & -.041 & .012 & -.210 & -3.287 & .001 & \\
\hline & $\mathrm{Age}^{2}$ & -.001 & $4.9 \mathrm{E}-04$ & -.130 & -2.885 & .004 & \\
\hline & Education & .344 & .050 & .436 & 6.820 & $<.001$ & \\
\hline & Education $^{2}$ & -.023 & .007 & -.146 & -3.114 & .002 & \\
\hline
\end{tabular}

Note. BTA $=$ Brief Test of Attention; SDMT $=$ Symbol Digital Modality Test 
Table 7.

Standard deviation (residual) for final multiple linear regression models.

\begin{tabular}{|c|c|c|}
\hline Score & Predicted value $\left(\widehat{Y}_{i}\right)$ & $S D_{e}$ (residual) \\
\hline \multirow{4}{*}{ M-WCST Categories } & $\leq 3,426$ & 1,350 \\
\hline & $3,427-5,264$ & 1,711 \\
\hline & $5,265-5,898$ & , 470 \\
\hline & $\geq 5,899$ & ,393 \\
\hline \multirow{4}{*}{ M-WCST Perseverative errors } & $\leq 0,769$ & 1,213 \\
\hline & $0,770-2,604$ & 1,408 \\
\hline & $2,605-8,968$ & 4,699 \\
\hline & $\geq 8,969$ & 6,281 \\
\hline \multirow{4}{*}{ M-WCST Total errors } & $<3,710$ & 3,698 \\
\hline & $3,711-7,654$ & 3,438 \\
\hline & $7,655-20,408$ & 9,728 \\
\hline & $\geq 20,409$ & 8,806 \\
\hline Stroop Word & All values & 12,957 \\
\hline Stroop Color & All values & 10,574 \\
\hline \multirow{4}{*}{ Stroop Word-Color } & $\leq 24,017$ & 5,599 \\
\hline & $24,018-35,801$ & 7,378 \\
\hline & $35,802-47,803$ & 8,710 \\
\hline & $\geq 47,804$ & 10,153 \\
\hline Stroop Interference & All values & 6,489 \\
\hline \multirow{4}{*}{ TMT-A } & $\leq 29,960$ & 9,152 \\
\hline & $29,961-42,235$ & 10,107 \\
\hline & $42,236-68,138$ & 16,377 \\
\hline & $\geq 68,139$ & 18,564 \\
\hline \multirow{4}{*}{ ТМТ-В } & $\leq 59,639$ & 16,592 \\
\hline & $59,640-92,463$ & 21,341 \\
\hline & $92,464-183,679$ & 53,304 \\
\hline & $\geq 189,680$ & 53,100 \\
\hline SDMT & All values & 8,432 \\
\hline \multirow{4}{*}{ BTA } & $\leq 11,801$ & 3,064 \\
\hline & $11,802-15,372$ & 3,924 \\
\hline & $15,373-16,725$ & 2,753 \\
\hline & $\geq 16,726$ & 2,671 \\
\hline
\end{tabular}


(A)

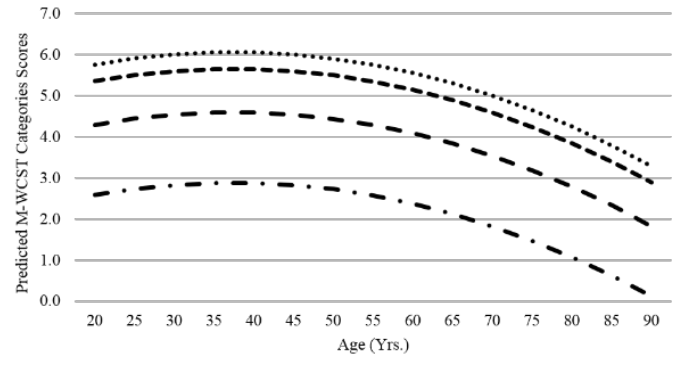

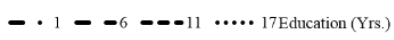

(C)

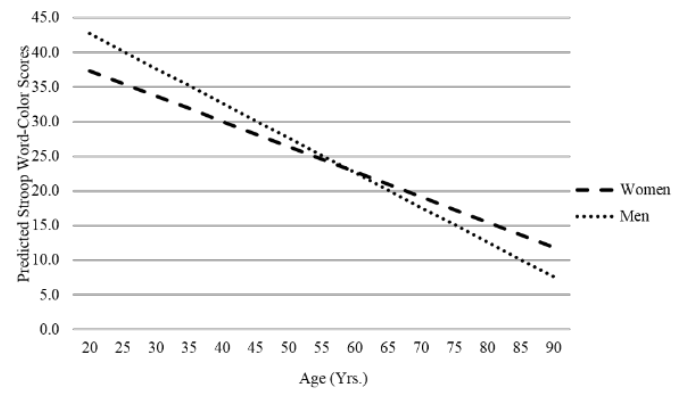

(E)

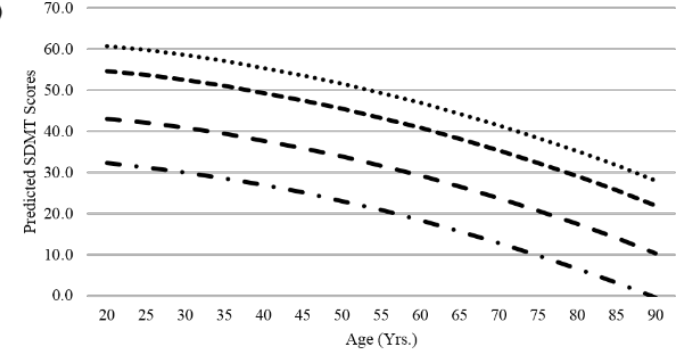

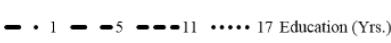

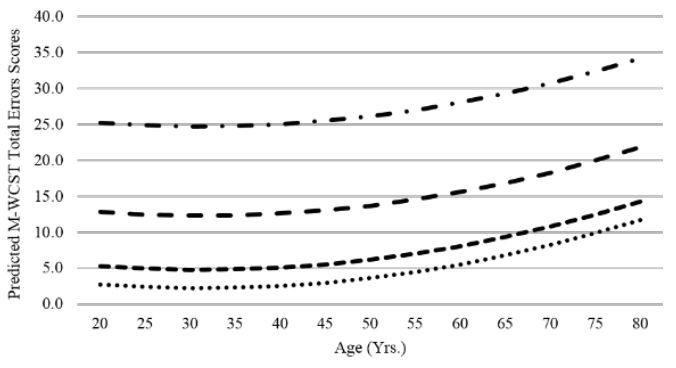

(B)

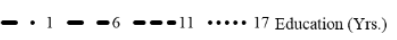

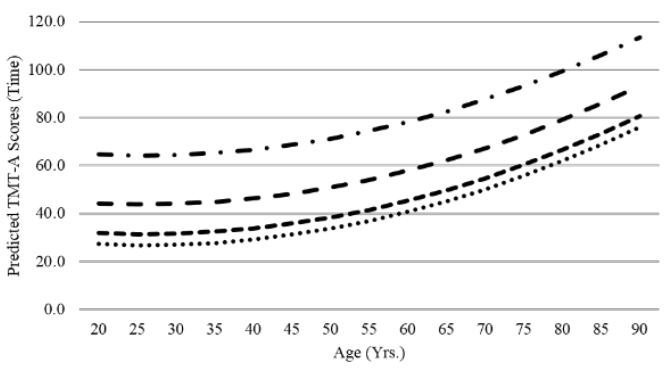

(D)

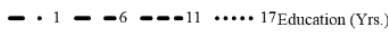

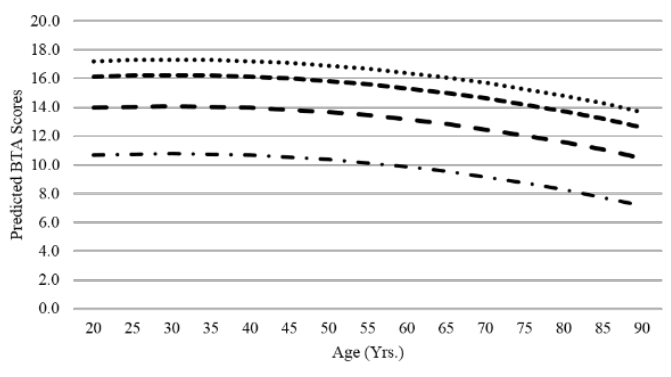

(F)

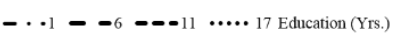

